\title{
S5ynthesis
}

International Scientific Conference of IT and Business-Related Research

\section{MOGUĆNOSTI SAVREMENIH UREĐAJA ZA ZAVARIVANJE MAG / MIG POSTUPKOM}

\section{THE POSSIBILITIES OF MODERN WELDING DEVICES FOR GMAW PROCESS}

\author{
Uroš Lukić1, Radica Prokić Cvetković1, Olivera Popović1, Radomir Jovičić2, Meri Burzićé, Branko Zrilić́ \\ ${ }^{1}$ Univerzitet u Beogradu - Mašinski fakultet, Kraljice Marije 16, Beograd, Srbija \\ ${ }^{2}$ Inovacioni centar Mašinskog fakulteta u Beogradu, Kraljice Marije 16, Beograd, Srbija \\ ${ }^{3}$ Fin import, Dobropoljska 33, Beograd, Srbija
}

\begin{abstract}
Apstrakt:
Kvalitet zavarenih spojeva zavisi od parametara procesa zavarivanja. Odstupanja parametara zavarivanja od definisanih vrednosti, koja se neminovno dešavaju tokom izrade zavarenog spoja, mogu dovesti do formiranja različitih tipova nesavršenosti. Formiranje nesavršenosti utiče na smanjenje nivoa kvaliteta zavarenog spoja. Savremeni uređaji za zavarivanje poseduju elektronske sisteme za automatsku korekciju parametara zavarivanja. U ovom radu prikazane su neke od najnovijih funkcija dostupnih na savremenim uređajima za elektrolučno zavarivanje topivom elektrodnom žicom u zaštitnoj atmosferi aktivnog ili inertnog gasa (MAG / MIG postupak) i njihov uticaj na kvalitet zavarenih spojeva.
\end{abstract}

\section{Ključne reči:}

parametri procesa zavarivanja, praćenje parametara u realnom vremenu, automatsko prilagođavanje parametara, funkcije kontrole električnog luka, kvalitet zavarenih spojeva.

\section{Abstract:}

The quality of welded joints depends on the parameters of the welding process. Deviations of the welding parameters from the defined values, which unavoidably occur during the welding process, can lead to the formation of different types of imperfections. Such imperfections contribute to reducing the quality level of the welded joints. Modern welding devices possess electronic systems for automatic correction of welding parameters. This paper presents some of the latest features available on modern devices for gas metal arc welding (GMAW process) and their impact on the quality of the welded joints.

\section{Key words:}

welding parameters, monitoring of parameters in real-time, automatic parameter adjustment, arc control functions, quality of welded joints.

\section{Napomena}

Ovaj rad proizašao je kao rezultat istraživanja u okviru projekta TR 35024 koji finansira Ministarstvo prosvete, nauke i tehnološkog razvoja Republike Srbije.

\section{UVOD}

Kvalitet zavarenih spojeva sve češće se ističe u prvi plan, usled povećanja striktnosti zahteva koje nameću poručioci kroz ugovore, ali i zakonodavna tela kroz tehničke standarde i regulativu. Osim toga, uvođenje sistema menadžmenta kvalitetom u inženjersku praksu nameće veći nadzor i kontrolu, nego što je to bio slučaj ranije, u raznim oblastima, pa tako i u oblasti projektovanja i izrade zavarenih konstrukcija.

Istovremeno, sve više se povećavaju razlike u veštinama između pojedinaca, pre svega onih koji su odgovorni za projektovanje i izradu zavarenih konstrukcija - inženjeri, tehnolozi, specijalisti, instruktori zavarivanja i zavarivači. Novi kadrovi, pre svega zavarivači, često se obučavaju na relativno kratkim kursevima, striktno ograničenim na upotrebu samo određenih postupaka zavarivanja, određenih dodatnih i osnovnih materijala, i samo određenih vrsta zavarenih spojeva i to u malom broju položaja. Stoga, ovako obučeni kadrovi ne stiču sve neophodne veštine potrebne za izradi svih vrsta zavarenih spojeva. U ovakvim situacjama upotreba funkcija koje omogućavaju savremeni uređaji za zavarivanje može značajno doprineti kvalitetu izrade zavarenih spojeva.
Obezbeđenje kvaliteta zavarenih spojeva, posebno kod velikih projekata i odgovornih konstrukcija, stvara potrebu za efikasnim upravljanjem kvalitetom. Kada je cilj da se zadovolje strogi zahtevi produktivnosti i istovremeno postigne zadovoljavajući kvalitet zavarenih spojeva, značaj kontrole procesa zavarivanja, kao i kontrole samog električnog luka, poprima veoma važnu ulogu.

Savremeni uređaji za zavarivanje proizvode se u invertorskoj tehnologiji. Prelazak na upotrebu elektronike u uređajima za zavarivanje omogućio je praćenje parametara elektrolučnog zavarivanja (jačina struje, napon električnog luka, brzina dodavanja elektrodne žice, protok zaštitnog gasa, brzina zavarivanja, itd.) u realnom vremenu, čime su se stekli preduslovi i mogućnosti za automatsku korekciju parametara procesa.

U današnje vreme gotovo da nema uređaja za elektrolučno zavarivanje, u višoj klasi, koji ne sadrži računarske komponente zadužene za praćenje parametara zavarivanja u realnom vremenu i automatsku korekciju parametara procesa. Na ovaj način, povećava se stabilnost električnog luka, omogućava se manji unos toplote u materijale koji se spajaju, čime se utiče na njihovu mikrostrukturu i mehaničke karakteristike, olakšava se rad zavarivača - lakše manipulisanje električnim lukom, što smanjuje verovatnoću nastajanja nesavršenosti u zavarenom spoju. Sve ovo utiče na obezbeđenje kvaliteta zavarenih spojeva. 


\section{FUNKCIJE ZA KONTROLU ELEKTRIČNOG LUKA}

Integracija i primena elektronskih komponenti i tehnika digitalne obrade signala u uređajima za zavarivanje omogućava istovremeno povećanje performansi procesa, produktivnosti i poboljšanje kvaliteta zavarenih spojeva. Uvođenje noviteta na polju hardvera predstavlja samo deo promena u ovoj oblasti.

Pored novih hardverskih rešenja i nova softverska rešenja koja prate te promene imaju značajan uticaj. Nova softverska rešenja na polju uređaja za zavarivanje korisnicima obezbeđuju značajne pogodnosti. Ova softverska rešenja grubo se mogu podeliti u dve kategorije: softveri koji poboljšavaju produktivnost procesa zavarivanja i softveri koja omogućavaju potpuno nove postupke i tehnike zavarivanja.

U prethodnoj deceniji razvijen je veliki broj funkcija namenjenih za upotrebu na uređajima za elektrolučno zavarivanje. Ove funkcije odnose se pre svega na kontrolu električnog luka, počevši od funkcija koje omogućavaju jednostavno uspostavljanje električnog luka, pa do naprednih funkcija koje obezbeđuju manji unos toplote u osnovne materijale koji se spajaju, različite načine prenosa dodatnog materijala kroz električni luk do metalnog kupatila, dobro uvarivanje i lakše vođenje električnog luka.

Pomenute funkcije uglavnom nisu standardizovane, nisu podjednako, niti u istim kombinacijama zastupljene na uređajima za zavarivanje. Različiti proizvođači ih navode pod različitim imenima, u sklopu svog brenda, i u zavisnosti od namene uređaja kombinuju različite funkcije.

S obzirom da nove generacije uređaja za zavarivanje poseduju memoriju i mikroprocesore, odnosno svojevrsne računarske sisteme specijalne namene, nove funkcije sa na određenim serijama proizvoda, pod uslovom da su adekvatna hardverska rešenja unapred integrisana, mogu dodavati po želji, jednostavnom instalacijom novog softvera ili aktivacijom pojedinačnih funkcija, unošenjem aktivacionih kodova. Na ovaj način, korisnicima se ostavlja mogućnost da u zavisnosti od potreba i finansijskih mogućnosti izaberu i aktiviraju samo određene grupe naprednih funkcija.

\subsection{FUNKCIJA EFEKTIVNOG PRILAGOĐAVANJA PARAMETARA KRATKOG ELEKTRIČNOG LUKA ZA ZAVARIVANJE KORENOG PROLAZA}

Funkcija efektivnog prilagođavanja parametara kratkog električnog luka povećava efikasnost procesa zavarivanja, prilikom izvođenja prvog prolaza - korenog prolaza zavarenog spoja, a namenjena je kako za manuelno elektrolučno zavarivanje topivom elektrodnom žicom u zaštiti aktivnog ili inertnog gasa (MAG / MIG postupkom), tako i za automatizovane postupke zavarivanja. Ova funkcija projektovana je sa namenom da obezbedi brže zavarivanje korenog prolaza, čak i u situacijama kada je zazor između osnovnih materijala neujednačen usled lošeg međusobnog pozicioniranja delova.

Upotrebom ove funkcije može se postići ušteda, jer se smanjuje potreba za sprovođenjem eventualnih reparacija prvog prolaza zavarenog spoja, a takođe nije potrebna ni upotreba keramičkih podloški prilikom zavarivanja, jer je unos toplote manji, čime je smanjena mogućnost curenja rastopljenog metala.

Kada je aktivirana ova funkcija dodatni materijal se kroz električni luk prenosi u režimu kratkog spoja, te je električni luk uspostavljen samo tokom polovine vremena trajanja ciklusa prenosa istopljene kapi dodatnog materijala. Ova funkcija sprečava nagle promene jačine struje tokom odvijanja ciklusa, koje su inače karakteristične za MAG / MIG postupak zavarivanja, kada se dodatni materijal prenosi kroz električni luk u režimu kratkog spoja. Tokom vremenskog intervala u kome električni luk nije uspostavljen ne dolazi do zagrevanja metala. $\mathrm{Na}$ ovaj način smanje se ukupni unos količine toplote u materijal. Usled toga, smanjena je zapremina istopljenog metala, što znatno olakšava rad zavarivača, pogotovu kada je zazor između delova veliki ili kada se zavarivanje vrši u nekom od prinudnih položaja (Zrilić et al., 2012).

\subsection{FUNKCIJA ZAVARIVANJA SA PROMENLJIVOM DUŽINOM SLOBODNOG KRAJA ELEKTRODNE ŽICE}

Do promene dužine slobodnog kraja elektrodne žice, prilikom upotrebe MAG / MIG postupka zavarivanja dolazi usled promene rastojanja između pištolja za zavarivanje i osnovnih materijala. Ove promene su posebno izražene prilikom manuelnog zavarivanja, a javljaju se kao posledica promene položaja ruke zavarivača ili geometrije osnovnih materijala.

Kao posledica promene dužine slobodnog kraja elektrodne žice, dolazi do promene električne otpornosti u električnom kolu, koje je zatvoreno kroz električni luk. Promena otpornosti dovodi do promene parametara zavarivanja, a pre svega jačine struje.

Oscilacije jačine struje dovode do destabilizacije električnog luka, što može uticati na formiranje različitih tipova nesavršenosti (na primer: nedovoljno uvarivanje, neujednačeno uvarivanje, rasprskavanje dodatnog materijala, neujednačena geometrija šava, nalepljivanje dodatnog materijala i slično), koje narušavaju kvalitet zavarenog spoja (Zrilić et al, 2012).

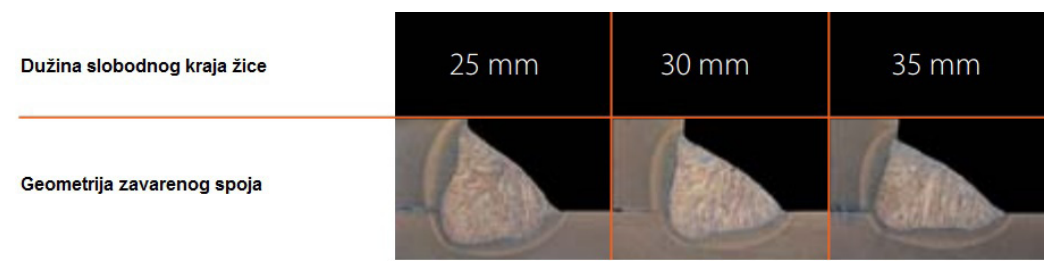

Slika 2. Uticaj dužine slobodnog kraja elektrodne žice na dubinu uvarivanja, kada se ne primenjuje funkcija zavarivanja sa promenljivom dužinom slobodnog kraja elektrodne žice

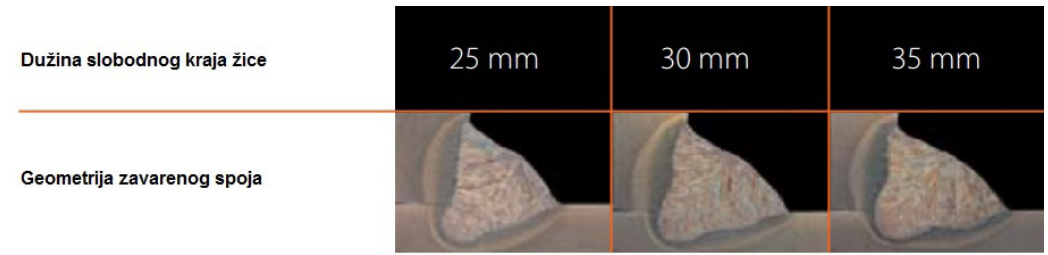

Slika 3. Uticaj dužine slobodnog kraja elektrodne žice na dubinu uvarivanja, kada je aktivirana funkcija zavarivanja sa promenljivom dužinom slobodnog kraja elektrodne žice 
Na slici 2 prikazana je zavisnost dubine uvarivanja od dužine slobodnog kraja elektrodne žice, kada se zavarivanje sprovodi MAG / MIG postupkom, bez upotrebe funkcije zavarivanja sa promeljivom dužinom slobodnog kraja elektrodne žice.

$\mathrm{Na}$ osnovu rezultata prikazanih na slici 2 može se zaključiti da se dubina uvarivanja smanjuje sa povećanjem dužine slobodnog kraja elektrodne žice.

Često se u praksi zavarivanje mora sprovoditi na nepristupačnim mestima, gde je održavanje konstantne dužine slobodnog kraja elektrodne žice, veoma komplikovano za zavarivača.

Ovaj problem rešava se upotrebom funkcije zavarivanja sa promenljivom dužinom slobodnog kraja elektrodne žice. Ovo tehničko rešenje omogućava kontinualno praćenje parametara zavarivanja u realnom vremenu. Sistem veoma brzo registruje promene električnog otpora u električnom kolu koje je zatvoreno kroz električni luk, a koje se javljaju kao posledica promene dužine slobodnog kraja elektrodne žice. $\mathrm{Na}$ osnovu toga, sistem prilagođava jačinu struje, kako bi je održao na definisanom nivou, čime se smanjuje verovatnoća pojave nesavršenosti u zavarenom spoju i utiče na kvalitet zavarenog spoja.

Na slici 3 prikazana je zavisnost dubine uvarivanja od dužine slobodnog kraja elektrodne žice, kada je aktivirana funkcija zavarivanja sa promenljivom dužinom slobodnog kraja elektrodne žice.

Na osnovu rezultata prikazanih na slici 3 može se zaključiti da se dubina uvarivanja ne menja značajno bez obzira na promenu dužine slobodnog kraja elektrodne žice, kada je aktivirana funkcija zavarivanja sa promenljivom dužinom slobodnog kraja elektrodne žice.

\subsection{FUNKCIJA ADAPTIVNOG PRILAGOĐAVANJA PARAMETARA ELEKTRIČNOG LUKA TOKOM PROCESA ZAVARIVANJA}

Ova funkcija se primenjuje na sinergetskim MAG / MIG uređajima za zavarivanje, koji omogućavaju impulsni prenos dodatnog materijala kroz električni luk, kao i prenos dodatnog materijala u spreju kroz električni luk. Osnovne namene ove funkcije su lakše definisanje optimalnih parametara procesa zavarivanja i povećanje produktivnosti. Kada je aktivirana, ova funkcija adaptivno prilagođava parametre električnog luka tokom odvijanja procesa zavarivanja, na osnovu kontinualnog praćenja parametara zavarivanjau realnom vremenu i izračunavanja razlika u fluktacijama jačine struje i napona električnog luka u odnosu na zadate parametre. Formule koje se koriste za izračunavanja su adaptivne, što obezbeđuje da korekcija i prilagođavanje parametara procesa zavarivanja ne bude povezano ni sa jednim specifičnim vremenskim parametrom, te električni luk u takvoj situaciji nije primoran da se ponaša po nekom specifičnom zakonu. Osnovni princip prilagođavanja i korekcije parametara procesa zavarivanja odnosi se na održavanje optimalne dužine električnog luka, tako da se električni luk fokusira na što manju površinu, kako bi se postigla što veća gustina energije (Uusitalo et al, 2009; Uusitalo, 2012).

Funkcija adaptivnog prilagođavanja parametara električnog luka tokom zavarivanja, aktivira se na upravljačkoj tabli uređaja za zavarivanje, tako što se podešava procentualni udeo broja kratkih spojeva.

U režimu impulsnog prenosa dodatnog materijala kroz električni luk, ova vrednost predstavlja učestalost ostvarivanja kratkog spoja nakon strujnog impulsa, tokom trenutne sekvence procesa. Na primer, ukoliko je podešavanje ovog parametra postavljeno na vrednost od 50\%, to znači da će se kratak spoj ostvariti nakon svakog drugog električnog impulsa. Na slici 4 prikazan je kratak spoj u jednoj od sekvenci impulsa.
Kada se dodatni materijal kroz električniluk prenosi u spreju, funkcija adaptivnog prilagođavanja parametara električnog luka tokom procesa zavarivanja sprovodi praćenje broja kratkih spojeva tokom odvijanja sekvence, sa ciljem da se broj kratkih spojeva održava na željenom nivou.

Kratki spojevi koje ostvaruju kapi istopljenog dodatnog materijala, koji se prenosi kroz električni luk, u kontaktu sa osnovnim materijalom ili metalnim kupatilom, potpomažu održavanje optimalne dužine električnog luka i omogućavaju korektno fokusiranje gustine energije. Stoga, kada je aktivirana, ova funkcija ne dozvoljava preveliko povećanje dužine električnog luka, jer bi to dovelo do rasipanja energije na veću površinu materijala.

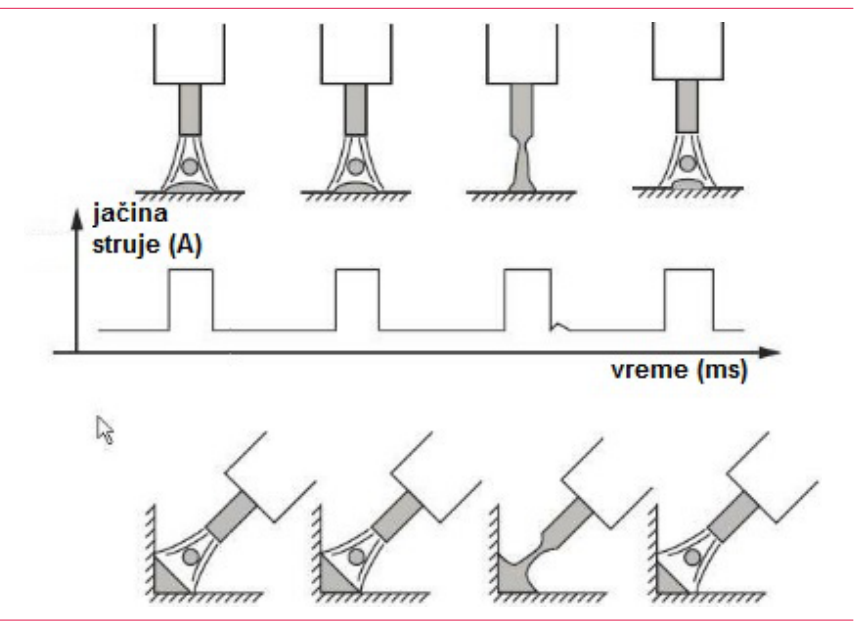

Slika 4. Kratak spoj u sekvenci impulsa

Funkcija adaptivnog prilagođavanja parametara električnog luka donosi značajne beneficije kod impulsnog prenosa dodatnog materijala kroz električni luk. Preciznije fokusiran električni luk omogućava manji unos količine toplote, za koji su istraživanja pokazala da ima presudan uticaj na zavarivanje čelika povišene čvrstoće, kao i pri zavarivanju aluminijuma. Takođe moguća je lakša kontrola vođenja električnog luka.

Rezultati sprovedenih ispitivanja pokazuju da se upotrebom funkcije adaptivnog prilagođavanja parametara električnog luka tokom procesa zavarivanja, postižu sledeće beneficije: manji unos toplote po jedinici dužine zavarenog spoja, veća brzina zavarivanja, bolja penetracija u korenu zavarenog spoja, te povećanje nominalne debljine spoja. Ovo se postiže na taj način što, kada je aktivirana, ova funkcija omogućava topljenje veće količine dodatnog materijala, u odnosu na iste parametre zavarivanja kada funkcija adaptivnog prilagođavanja parametara električnog luka nije aktivirana (Uusitalo, 2012).

Kada je debljina materijala veća od $30 \mathrm{~mm}$ smatra se da se spajaju debeli materijali. Tada se zahteva veća dužina slobodnog kraja elektrodne žice prilikom primene MAG / MIG postupka zavarivanja, koja prevazilazi uobičajenu vrednost od $15 \mathrm{~mm}$ do $25 \mathrm{~mm}$. Promena u dužini slobodnog kraja elektrodne žice utiče na vrednost jačine struje za naponski kontrolisan električni luk. Kada je dužina slobodnog kraja elektrodne žice veća od uobičajenih vrednosti jačina struje se smanjuje. Ovo utiče na efikasnost zavarivanja i na unetu količinu toplote po jedinici dužine šava. Može biti teško da se vrh pištolja za zavarivanje primakne dovoljno blizu kada je žleb uzak, što zahteva povećanje slobodnog kraja elektrodne žice. Cilj zavarivača je da pokuša da proces zavarivanja održi efikasnim. Kada je dužina slobodnog kraja žice veća od normalne vrednosti električni luk ne može biti fokusiran precizno na dno žleba, te stoga dolazi do skretanja električnog luka na stranice žleba. Funkcija adaptivnog prilagođavanja parametara električnog luka dovodi do sužavanja 
električnog luka i omogućava fokusiranje energije na manju površinu, dublje u žleb, što zavarivaču omogućava lakšu kontrolu vođenja električnog luka, kao što je prikazano na slici 5.

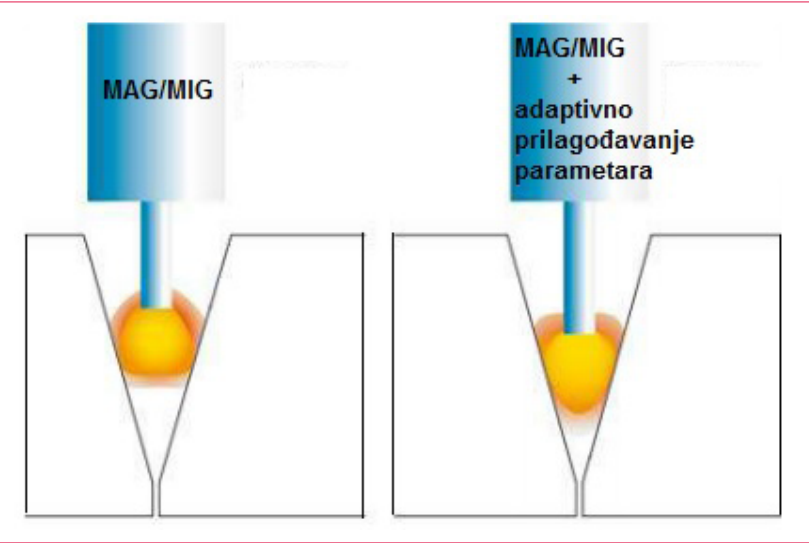

Slika 5. Fokusiranje električnog luka upotrebom funkcije adaptivnog prilagođavanja parametara električnog luka tokom procesa zavarivanja

Na slivi 6 prikazan je uticaj funkcije adaptivnog prilagođavanja parametara električnog luka tokom procesa zavarivanja na gemoetriju metala šava. Zavareni spoj prikazan na levoj strani slike izrađen je bez upotrebe ove funkcije, sa prenosom dodatnog materijala u spreju kroz električni luk. Spoj prikazan na desnoj strani slike izrađen je uz upotrebu funkcije adaptivnog prilagođavanja parametara električnog luka tokom procesa zavarivanja.

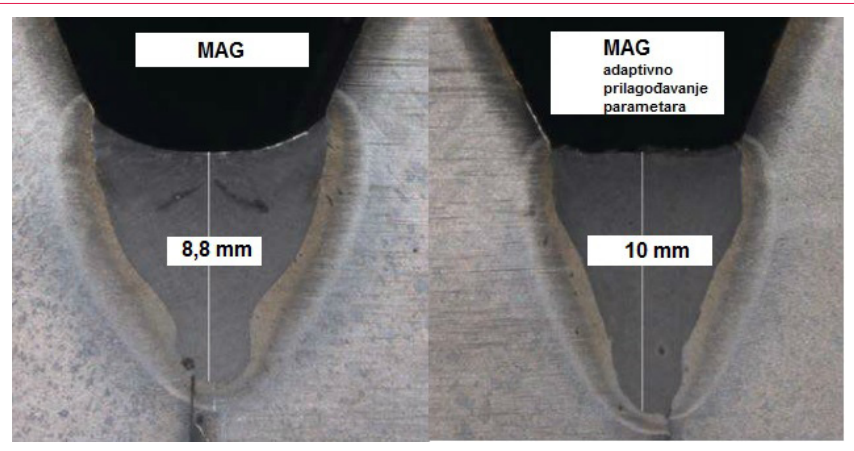

Slika 6. Uticaj funkcije adaptivnog prilagođavanja parametara električnog luka tokom procesa zavarivanja na gemoetriju metala šava

Upotreba ove funkcije smanjuje potrebe za finim podešavanjima električnog luka, jer velika gustina energije obezbeđuje da električni luk bude optimalno fokusiran u metalnom kupatilu. Usled poboljšanja fokusiranja električnog luka, brzina zavarivanja može se povećati, a u uskim žlebovima postići bolja penetracija, nego kada se ova funkcija ne koristi. U prinudnim položajima zavarivanja funkcija obezbeđuje bolju kontrolu vođenja električnog luka i povećanje brzine zavarivanja.
Brzina zavarivanja povećava se prilikom prelaska sa manuelnog na mehanizovano zavarivanje. Kombinacija ove funkcije, prenosa dodatnog materijala u spreju kroz električni luk i automatskog vođenja električnog luka je odlična sprega za povećanje produktivnosti.

Funkcija adaptivnog prilagođavanja parametara električnog luka smanjuje unetu količinu toplote. Na ovaj način smanjuju se deformacije delova koji se zavaruju, štedi se električna energija, a smanjuje se i potreba za obradom delova nakon zavarivanja kako bi se ispravili. Ovo je značajan doprinos prilikom zavarivanja materijala koji imaju malu krutost.

\section{REZIME}

Postupci zavarivanja predstavljaju najefikasniji poznati način spajanja metala. S obzirom na ovu činjenicu, uređaji za zavarivanje konstantno se unapređuju. Savremeni uređaji za zavarivanje sadrže specijalne računarske sisteme namenjene za praćenje parametara procesa zavarivanja u realnom vremenu i automatsku regulaciju električnog luka. Upotrebom specifičnih funkcija proces rada zavarivača može se znatno olakšati uz istovremeno ispunjavanje zahteva produktivnosti i kvaliteta zavarenih spojeva, pri čemu se uticaj zavarivača na kvalitet može do određene mere redukovati. Softverska regulacija parametara električnog luka, tokom procesa zavarivanja, je relativno jeftino rešenje koje donosi mnogobrojne beneficije. Sva druga rešenja za unapređenje elektrolučnog zavarivanja su znatno skuplja, jer zahtevaju nabavku specifične opreme, kao što su uređaji za zavarivanje tankih limova upotrebom hladnog prenosa materijala. Međutim, ovakva rešenja nisu opšte primenljiva za obavljanje različitih zadataka. Funkcije opisane u ovom radu još uvek ne predstavljaju opšte prihvaćena rešenja i zastupljene su samo na uređajima više klase.

\section{LITERATURA}

Uusitalo, J., Peltola, T., Kumpulainen, J., \& Veikkolainen, M. (2009). Novel tailored welding arcs help welders meet quality and productivity demands. In: Proceedings of the IIW International Conference on Advanced Processes and Technologies in Welding and Allied Technologies. 16-17 July 2009 (pp. 1518). Singapore: Singapore Welding Society.

Uusitalo, J. (2012). Focus on arc control leads to superior quality. Kemppi Pro News, pp. 17-21. Preuzeto 14. januara 2015. sa http://productinfo.kemppi.com/flipbook/pronews_2012/en/ files/assets/common/downloads/ProNews\%202012\%20EN. pdf

Zrilić, B., Pantelić, N., Jovičić, R. \& Jovičić, D. (2012). Inovacije u tehnologiji zavarivačkog luka. Zavarivanje i zavarene konstrukcije. LVII (4), 163-167. 